\title{
Differential Diagnosis of Inflammatory Bowel Disease: What Is the Role of Colonoscopy?
}

\author{
Sung-Ae Jung \\ Department of Internal Medicine, Ewha Womans University School of Medicine, Seoul, Korea
}

\begin{abstract}
Colonoscopy plays a crucial role in the diagnosis, treatment and follow-up monitoring of inflammatory bowel disease (IBD). Practitioners should be well informed of the colonoscopic findings of IBD to prevent the misdiagnosis, overtreatment or delayed treatment. Distinguishing between Crohn's disease and ulcerative colitis is essential in terms of pharmacological treatment, surgical decision-making, and prognosis. But there are still lesions with difficulty in differentiation that approximately $10 \%$ of the patients fall into the category of indeterminate colitis. Efforts are needed to carefully select treatment approach appropriate for each patient by providing a precise diagnosis on the extent and degree of lesions as well as to accurately delineate the lesions to assure that they are compared in subsequent rounds of follow-up monitoring in order to allow redetermination and adjustment of the treatment.
\end{abstract}

Key Words: Inflammatory bowel disease; Colonoscopy; Differential diagnosis

\section{INTRODUCTION}

Colonoscopy plays a crucial role in the diagnosis, treatment and follow-up monitoring of inflammatory bowel disease (IBD). Because there is no single manifestation particular to IBD, combination of clinical, endoscopic, and pathological manifestations must be evaluated to obtain accurate diagnosis. Colonoscopy is an applicable tool for diagnosis of IBD, by 1 ) distinguishing between ulcerative colitis, Crohn's disease and other medical conditions, 2) identifying the severity and extent of lesions, and 3) collecting tissues required for confirmation of pathological opinions. Clinicians decide therapeutic strategies regarding pharmacological treatment, surgery, and treatment of complications stemming from IBD based not only upon diagnosis through colonoscopy but also upon the manifestation of colonic mucosal lesions. Endoscopic manifestations of IBD, however, vary among patients and even a single patient may show various clinical manifestations dur-

\footnotetext{
Received: July 11, 2012 Revised: July 25, 2012

Accepted: July 25, 2012

Correspondence: Sung-Ae Jung

Department of Internal Medicine, Ewha Womans University School of Medicine, 1071 Anyangcheon-ro, Yangcheon-gu, Seoul 158-710, Korea

Tel: +82-2-2650-5053, Fax: +82-2-2655-2076, E-mail: jassa@ewha.ac.kr

(c) This is an Open Access article distributed under the terms of the Creative Commons Attribution Non-Commercial License (http://creativecommons.org/ licenses/by-nc/3.0) which permits unrestricted non-commercial use, distribution, and reproduction in any medium, provided the original work is properly cited.
}

ing follow-up monitoring. Therefore, decisions must be made based on various endoscopic and clinical manifestations. This article will review the colonoscopic manifestations of IBD, which distinguish IBD from other diseases for diagnosis, especially for differential diagnosis, of ulcerative colitis and Crohn's disease, and will explore the criteria of colonic mucosal healing in order to determine the extent and severity of lesions.

\section{COLONOSCOPIC MANIFESTATION OF INFLAMMATORY BOWEL DISEASE}

\section{Pathognomonic endoscopic manifestation of ulcerative colitis}

Several pathognomonic manifestations of mucosal inflammation due to ulcerative colitis are helpful in distinguishing ulcerative colitis from Crohn's disease and other forms of colitis. Inflammation or ulceration of mucosa initiates from the superjacent area of the anal canal and is distributed in a continuous and symmetrical manner. Skip lesions are not commonly found. The extent of lesions may vary from those limited in the rectum to those extended to the entire colon. The boundary between the lesion area and the normal mucosa is clearly delineated. The initial manifestations that can be observed through the colonoscopy are erythema and hyperemia of the colonic mucosa. Erythema occurs due to the capillary ectasia of the mucosa and is suggestive of active inflammation 
particularly when accompanied by the loss of vascularity, granularity or mucopurulent exudates of the mucosa. Since erythematous colonic mucosae are characterized by the fragility, they tend to bleed easily with minor stimulation. When the fragility is significant, it may show spontaneous bleeding without any contact. Granularity indicates that the surface of mucosa shows unevenness and irregularity, and the degree varies in terms of fineness or roughness. ${ }^{1-3}$

Ulcers are generally tiny in size and distributed in a limited fashion across the surface, but as ulcers develop further through their confluence, they grow in size and form linear or circular ulcers. Because mucosal inflammation is pathognomonic in ulcerative colitis, the mucosa surrounding ulcers is also accompanied by erythema or fragility. As ulcers worsen, a wide range of mucosal exfoliation leaves only a portion of the mucosa; when ulcers heal and are replaced with scar tissue; the remaining mucosa protrudes as granular or nodular mucosa, forming polypoid lesions known as pseudopolyps, and in most cases a group of these pseudopolyps occur simultaneously in various sizes and forms. The surface of pseudopolyps may be covered with exudates and accompanied by erosion or ulcers. Because most of them are unlikely to show malignant degeneration, removal is unnecessary. However, when a pseudopolyp exists independently, is larger than $1 \mathrm{~cm}$, or when the base of the pseudopolyp, with a large and irregular shape, shows a hemorrhagic surface, diagnosis must be made cautiously based upon biopsy or polypectomy for the assessement of the dysplasia associated lesion or mass. If the haustral folds thicken and the hypertrophy or contracture of the muscle layer due to prolonged inflammatory change, the lumen narrows and the haustral folds can be lost. As a result, lumen may appear tube-shaped or show partial stenosis. ${ }^{4,5}$

Biopsy must be conducted both in the inflamed lesion and in the mucosa that appears macroscopically normal in the most proximal part of the lesion. Ulcerative colitis may be ruled out when rectal biopsy results appear normal both macroscopically and microscopically. According to a recent study, among the prospective cohort of patients with ulcerative colitis who showed no signs of Crohn's disease, approximately $44 \%$ developed skip lesions and about $13 \%$ showed lesions that did not involve the rectum. ${ }^{6}$ In addition, there were other cases in which patients with ulcerative proctitis or left colitis have inflammation only in the region surrounding the appendiceal orifice without involving the rest of the colon. The inflammation around the appendiceal orifice also shows erythema, edema, granularity, fragility, and ulceration, consistent with the manifestations of distal colonic mucosa. The clinical significance of inflammation around the appendiceal orifice varies among studies; when the patients who manifest both active ulcerative colitis in the distal regions and inflammation surrounding the appendiceal orifice are compared with those without such inflammation, conflicting results have been reported suggesting either that both the former are more likely to achieve remission or that no differences can be found between the two groups. ${ }^{78}$ Generally, the small intestine is not involved, but among $10 \%$ of patients with diffuse active colitis, backwash ileitis is accompanied by a few centimeters of specific inflammation in the terminal ileum. ${ }^{9}$

\section{Pathognomonic endoscopic manifestation of Crohn's disease}

Unlike ulcerative colitis, Crohn's disease may occur within any area of the digestive tract showing asymmetrical, discontinuous, focal, and patch characteristics. Inflammatory lesions are surrounded by normal mucosa, forming skip lesions. ${ }^{4}$ The rectum is spared in many cases where Crohn's disease invades the large intestine, and tiny aphthous erosions can be observed by colonoscopy at the initial stage. Since small ulcers can adjoin the ileocecal valve or exist in the terminal ileum, it is imperative to examine the terminal ileum when conducting colonoscopy to patients clinically suspected of suffering from Crohn's disease. Ulcers may persist as aphthous or shallow ulcers on the mucosal surface, or grow to form deeper ulcers. Ulcers from Crohn's disease show clear boundaries; the mucosa surrounding the ulcers appears normal or almost normal and long longitudinal ulcers run in parallel with the large intestine. Multiple ulcers may be discovered in parallel, and if inflammation and edema beneath the mucosa worsen and form superficial sulcus, the intestinal mucosa shows a nodular surface in a continual and regular shape, forming a cobblestone appearance. When inflammation worsens and longitudinal ulcers break out throughout the entire colon, it becomes difficult to distinguish Crohn's disease from severe ulcerative colitis; pseudopolyps may also occur in cases of Crohn's disease. ${ }^{10,11}$

Biopsy is conducted on areas inflicted with erosion or ulcers, and the biopsy of adjacent normal mucosa may identify skip lesions. Biopsy for marginal ulcers or aphthous erosion possesses the highest potential for revealing granuloma, which is difficult to find in cobblestone mucosa. Endoscopic biopsy can identify granuloma in $15 \%$ to $36 \%$ of cases; however, its clinical significance is limited to assisting a definite diagnosis. On the other hand, if granuloma is found in the seemingly normal rectum mucosa of a Crohn's disease patient with invasion into the large intestine, this may help distinguish it from ulcerative colitis. ${ }^{12-14}$

Previously, the diagnosis of Crohn's disease in the small intestine has been based on observation of the terminal ileum through colonoscopy, radiological examination of the small intestine, and examination through upper gastrointestinal 
endoscopy. A recent development of enteroscopy, however, has made it possible to identify and conduct biopsy to the lesions, whereas capsule endoscopy can provide supplemental information. ${ }^{15}$

\section{DISTINGUISHING BETWEEN ULCERATIVE COLITIS AND CROHN'S DISEASE}

Distinguishing between ulcerative colitis and Crohn's dis-
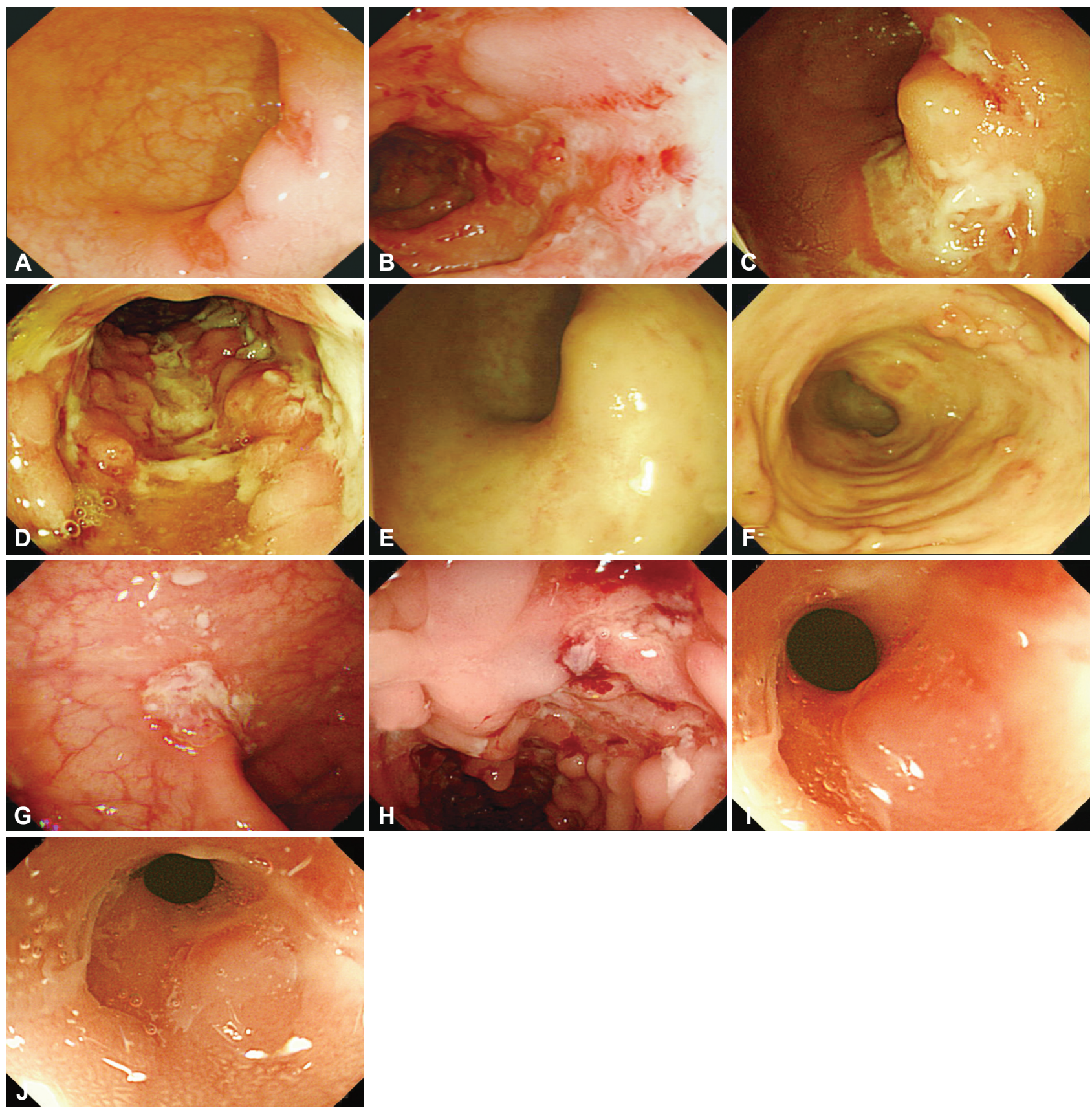

Fig. 1. Chronographic alteration in endoscopic findings of typical Crohn's disease. A 37-year-old female had colonoscopy with complaints of diarrhea. At initial diagnosis, multiple aphthous erosion and linear ulcer with normal surrounding mucosa were noted (A, B). She was diagnosed as Crohn's disease. After 2 years, colonoscopy revealed the ulcers were deeper with typical cobblestone appearance caused by numerous, confluent ulcerations (C, D). She had been treated with combination of steroid and immunosuppressants. Five months after the treatment, ulcers were healed with fibrotic change (E, F) with resolution of symptoms, and complete remission was achieved. Four years after the initial diagnosis, symptoms were exacerbated and follow-up colonoscopy showed deep ulcers with recurrent cobble stone appearance $(G, H)$ that biologic agent was initiated. Even though the ulcerative lesions in the mucosa improved, stenosis followed, eventually leading to balloon dilation $(\mathrm{I}, \mathrm{J})$. Since the patient clearly showed natural progression during the treatment of Crohn's disease, there was no confusion in the diagnosis of Crohn's disease. 


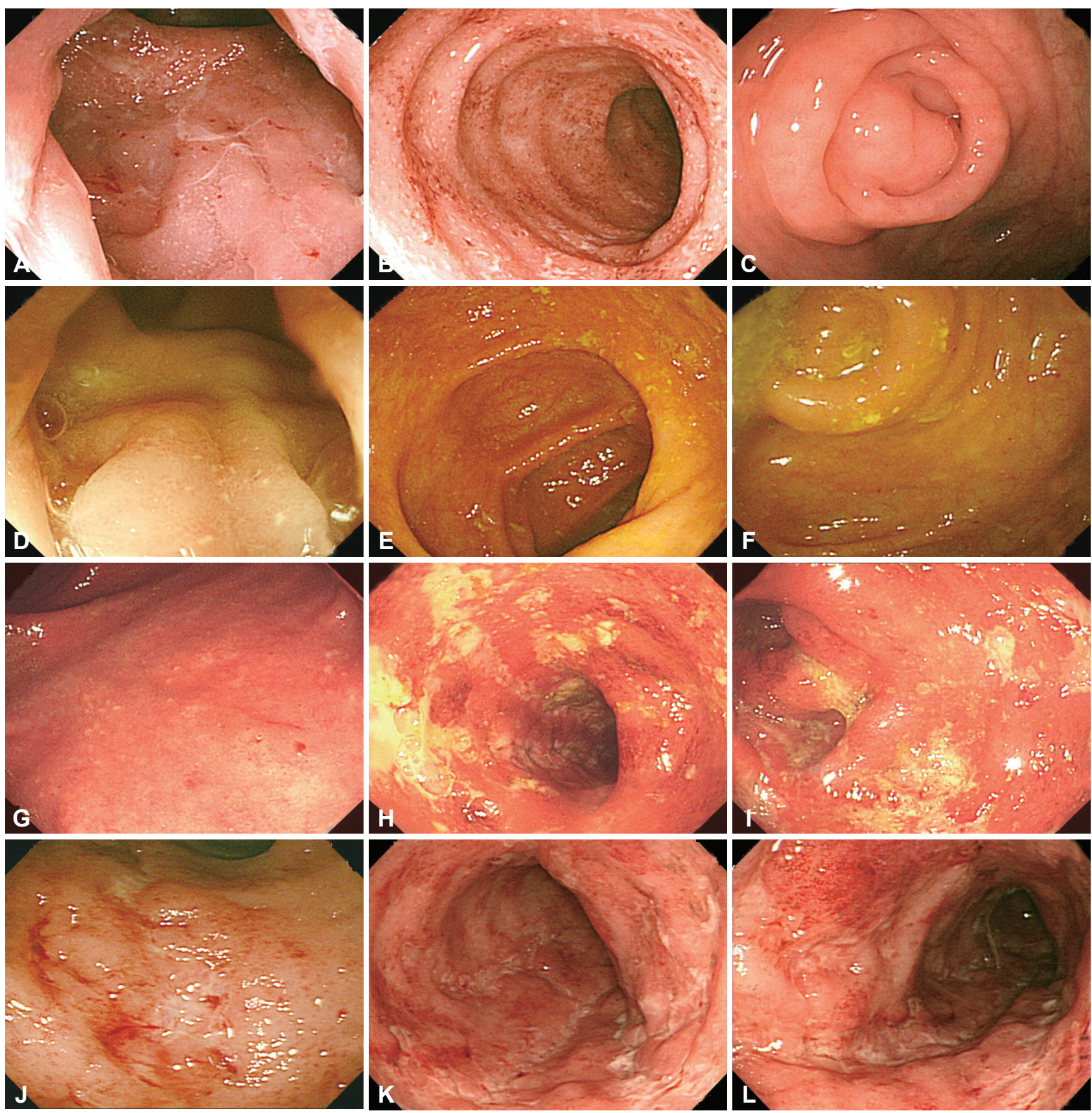

Fig. 2. Confusing endoscopic findings of ulcerative colitis. A 22-year-old male had colonoscopy with complaints of loose stool. At initial diagnosis, diffuse erythema with friable and granular mucosal change was noted from the rectum to the descending colon without involvement of the right colon (A, B, C). He was diagnosed as ulcerative colitis and had been treated for 1 year, and complete remission was achieved $(D, E, F)$. Four years after the diagnosis, during the follow-up colonoscopy, multiple longitudinal ulcers without involvement of rectum were noted which could have been confused with Crohn's disese if the patient did not have colonoscopy previously (G, H, I). Colonoscopic findings were more compatible with ulcerative colitis 8 months later compared with the latest exam $(J, K, L)$.

ease is crucial in terms of pharmacological treatment, surgical decision-making, and prognosis. ${ }^{1,4}$ Although colonoscopy of the terminal ileum is sufficient to differentiate the two diseases in most cases, approximately $10 \%$ of patients fall into the category of indeterminate colitis, which is relatively difficult to distinguish. ${ }^{16}$ The results of 22-month duration of follow-up showed that 350 patients with IBD indicated that in
$89 \%$ of cases ulcerative colitis and Crohn's disease could be differentiated upon diagnosis.

The initial diagnosis was adjusted in about $4 \%$, and the two diseases remained indistinguishable in approximately $7 \%$. When inflammation is severe, they become more difficult to distinguish. Nonetheless, as for critical features in making a distinction between the two diseases, Crohn's disease is high- 

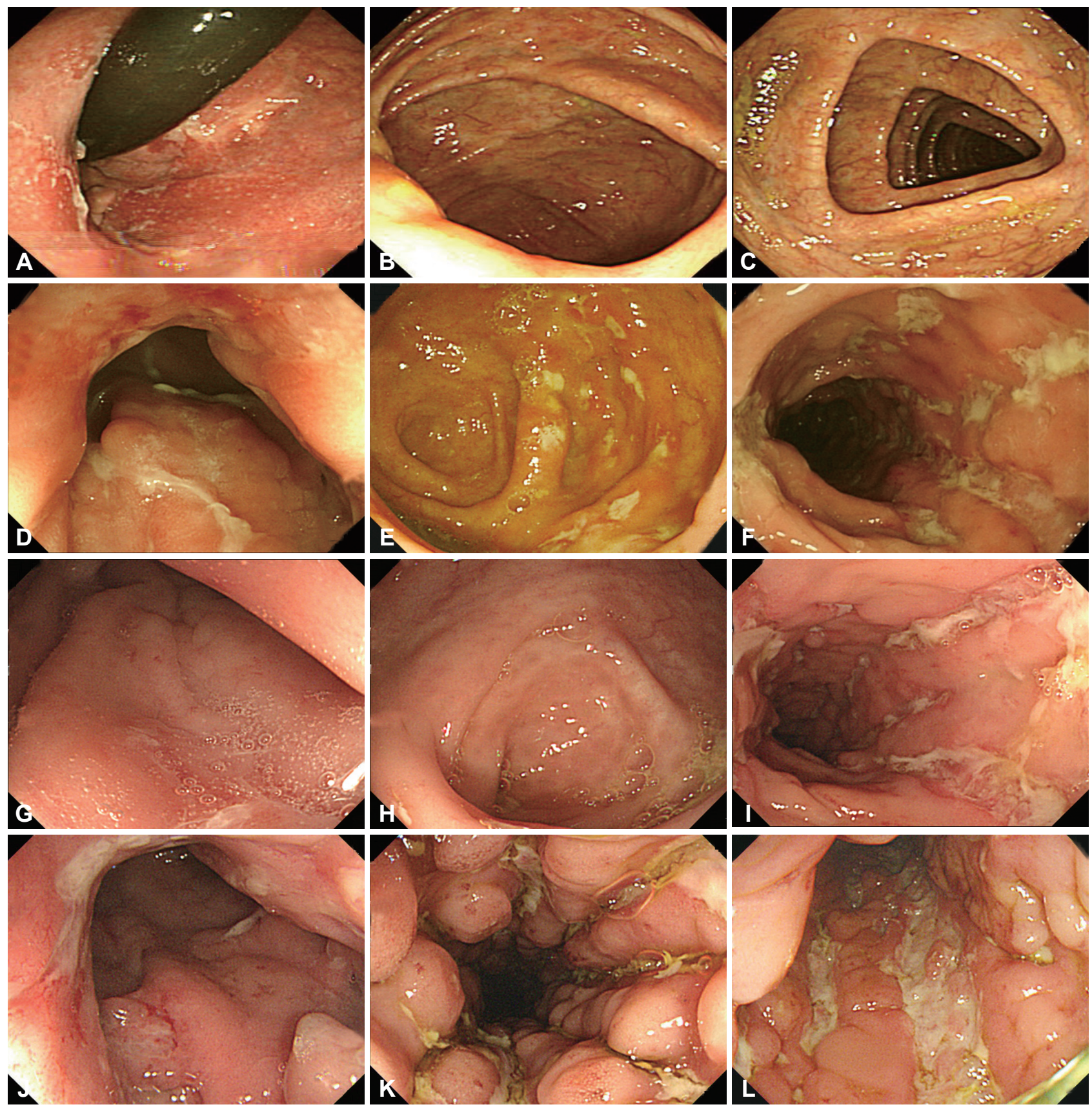

Fig. 3. Confusing endoscopic findings of Crohn's disease. A 22-year-old male had colonoscopy with complaints of mucoid stool. Initial findings showed friable mucosal change with granularity noted in the rectum without any involvement of the rest of the colon (A, B, C). The patient was diagnosed as ulcerative proctitis. One year later, disease was extended to the entire colon and the patient had systemic treatment with consideration of the extensive ulcerative colitis $(D, E, F)$. Six months after the treatment, follow-up colonoscopy revealed that the rectum was spared with multiple linear skipped ulcer $(G, H, I)$. Four years after the initial diagnosis, the rectum was involved again confusing the diagnosis. One year after the latest exam, cobblestone appearance was found (J, K, L). Final diagnosis was adjusted to Crohn's disease since he was initially diagnosed as ulcerative colitis 4 years ago

ly likely to be diagnosed among patients who manifest skip lesions, perianal lesions, and a cobblestone appearance, whereas a continuous granularity of the mucosa accompanied by erosions or diminutive ulcers is found more often with ulcerative colitis. ${ }^{17}$ One- to 2 -year follow-up monitoring in a large-scale study demonstrated that the diagnosis were changed in about
$10 \%$ of cases. ${ }^{18}$ Thirty-three percent of patients with indeterminate colitis were diagnosed with ulcerative colitis and about $17 \%$ with Crohn's disease. ${ }^{19}$ These results demonstrate the value of review even when ulcerative colitis or Crohn's disease are confirmed, in addition to cases of unclear diagnosis (Figs. 1-3). ${ }^{20}$ 


\section{ENDOSCOPIC DIFFERENTIATION FROM OTHER DISEASES}

\section{Infectious colitis}

The chief complaint of patients with infectious colitis is diarrhea. Because the symptom is sometimes accompanied by bloody stool, it is important to distinguish the infectious colitis from ulcerative colitis. ${ }^{1,16}$ In one prospective study, onethird of patients with bloody diarrhea who were suspected of IBD were found suffering from infectious colitis. ${ }^{21}$ However, diagnosis can be complicated by the fact that IBD patients may have an accompanying infection as well. Unlike IBD, infectious colitis will improve on its own and show rapid progress in many cases, thus requiring careful observation of its clinical progress. In the case of mucosal lesions, the rectum remains intact, whereas ulcers covered with yellow exudates and more serious flaring are observed. Biopsy is able to rule out infectious colitis based on the chronic inflammatory change observed in cases of ulcerative colitis or Crohn's disease, such as manifestations of crypt architecture distortion, crypt atrophy, and basal lymphoid aggregates. Furthermore, it is also possible to diagnose infectious colitis by finding a pseudomembrane, viral inclusion or amoeba trophozoites. Culture tests using biopsy tissues are generally more helpful than fecal culture tests in establishing pathogenic organisms. For treatment of ulcerative colitis, one must keep in mind that ulcerative colitis may worsen or fail to respond to treatment due to superinfection with cytomegalovirus (CMV). The use of steroid or immunosuppressant treatment for ulcerative colitis may provide an ideal environment for infection or inhabitation of CMV. CMV is highly likely to be found in refractory ulcerative colitis, which does not easily respond to treatment. In some cases, ulcerative colitis has been shown to improve when treated with the antiviral agent gancyclovir. Therefore, it is advisable to closely examine biopsy results and attempt to identify superinfection with CMV prior to making treatment decisions, including surgery, on patients with severe ulcerative colitis or refractory ulcerative colitis. ${ }^{22-24}$

\section{Ischemic colitis}

Ischemic colitis is mainly found among the elderly, and, in some cases, is accompanied by risk factors such as heart diseases or vascular sclerosis. Most patients with ischemic colitis suffer sudden abdominal pain and bloody stool prior to seeking treatment. Colonoscopy reveals mucosal edema and erythema, with the rectum remaining intact. This type of colitis often invades the rectosigmoid junction or splenic flexure, which may suffer from insufficient supply of blood. Lesions cover the entire lumen and invade only a focal segment, leaving the other regions with normal mucosa. The condition of the mucosal lesions is similar to that of ulcerative colitis, but it is possible to distinguish ischemic colitis from ulcerative colitis based on differences in clinical progression. It is also important to distinguish ischemic colitis from Crohn's disease, which may be possible by observation of the longitudinal shape of the ulcers. ${ }^{1,16}$

\section{Radiological colitis}

When patients with a history of receiving radiological treatment for prostate cancer or cervical cancer suffer from bloody diarrhea, it is common to suspect radiological colitis which mainly invades the proximal rectum and distal sigmoid colon. Distinguishing radiological colitis from ulcerative colitis is a simple matter, since the former demonstrates pathognomonic features such as mucosal fragility, mucosal granularity, and telangiectasia. However, the distinction may become less clear as symptoms worsen, leading to more hemorrhages and increasingly serious ulcers. Because the rectum, which is superjacent to the anus, remains intact, it is important to make careful observations when inserting the endoscope to verify the lesions after rinsing the mucosa. ${ }^{1,16}$

\section{DETERMINATION OF CRITERIA FOR EXTENT AND SEVERITY OF LESIONS (MUCOSAL HEALING)}

Identification of the location and the extent of lesions are critical for determining the appropriate medication and the administration methods for pharmacological treatment. It is also a necessary component for predicting the risk of colorectal cancer and determining the need for surgery. ${ }^{1-4}$ Because colonoscopy with accompanying biopsy is more sensitive for revealing the extent of lesions than computed tomography colonography, the extent of lesions should be determined after the biopsy is performed during colonoscopy, in the most proximal region that is macroscopically identifiable.

In clinical practice, suppositories or enema therapy are administered for lesions limited to the rectum or left-side colitis, whereas oral medication is administered in combination with transanal treatment when lesions invaded the right colon..$^{10,11}$ However, the extent of lesions in IBD does not remain fixed, but can be reduced or expanded during the treatment period. ${ }^{25}$ In a long term follow-up study of approximately 25 years, 53\% of ulcerative colitis cases that were initially limited to the rectum progressed into the sigmoid colon. ${ }^{26}$ It is therefore important to periodically identify sites invaded by lesions, because the risk of colorectal cancer associated with ulcerative colitis is correlated with the degree and extent of the inflammation invasion. Although determining the severity of lesions remains controversial in mild to moderate colitis, it can be a crucial 
indicator for ascertaining the course of treatment in patients with severe colitis. To date, the focus of treatment has been on assuaging the symptoms of the disease rather than on a com- plete regeneration of the mucosa. With the introduction of immunosuppressants and biological medicines, the significance of endoscopic remission has come to the fore, and pa-

Table 1. Endoscopic Scores for Crohn's Disease ${ }^{32,33}$

\begin{tabular}{|c|c|c|c|c|}
\hline IBD score & Validation & Endoscopic variables & Strengths & Weakness \\
\hline $\begin{array}{l}\text { Crohn's } \\
\text { disease EIS }\end{array}$ & Yes & $\begin{array}{l}\text { Deep ulceration } \\
\text { and inflammation }\end{array}$ & $\begin{array}{l}\text { Gold standard for the endoscopic } \\
\text { assessment of Crohn's disease, } \\
\text { reproducible }\end{array}$ & $\begin{array}{l}\text { Complex (lot of variables and scores } \\
\text { range from } 0 \text { to } 44 \text { ). } \\
\text { Experience is required, difficult to use } \\
\text { in clinical practice, no validated } \\
\text { definition of } \mathrm{MH}\end{array}$ \\
\hline $\begin{array}{l}\text { SES for Crohn's } \\
\text { disease }\end{array}$ & Yes & $\begin{array}{l}\text { Ulcers, inflammation, } \\
\text { and narrowing }\end{array}$ & $\begin{array}{l}\text { Simplified endoscopic score } \\
\text { for Crohn's disease, Correlated } \\
\text { to Crohn's disease EIS }\end{array}$ & $\begin{array}{l}\text { Validated in only one study, score range } \\
\text { from } 0 \text { to } 60 \text {, no validated definition } \\
\text { of } \mathrm{MH}\end{array}$ \\
\hline $\begin{array}{l}\text { Rutgeerts } \\
\text { score }\end{array}$ & No & $\begin{array}{l}\text { Aphthoid lesions, } \\
\text { inflammation, } \\
\text { ulcers, nodules, } \\
\text { and narrowing }\end{array}$ & $\begin{array}{l}\text { Gold standard for the assessment } \\
\text { of postoperative disease recurrence, } \\
\text { validated cut-off value for the prediction } \\
\text { of clinical relapse }\end{array}$ & $\begin{array}{l}\text { Can be used only in setting of assessing } \\
\text { the postoperative recurrence of disease, } \\
\text { no utility as an end point for endoscopic } \\
\text { remission in therapeutic trials }\end{array}$ \\
\hline
\end{tabular}

IBD, inflammatory bowel disease; EIS, endoscopic index of severity; $\mathrm{MH}$, mucosal healing; SES, simple endoscopic sore.

Table 2. Endoscopic Scores for Ulcerative Colitis ${ }^{27,34-36}$

\begin{tabular}{|c|c|c|c|c|}
\hline IBD score & Validation & Endoscopic variables & Strengths & Weakness \\
\hline $\begin{array}{l}\text { Mayo endoscopic } \\
\text { subscore }\end{array}$ & No & $\begin{array}{l}\text { Erythema, vascular pattern, } \\
\text { friability, bleeding, erosions, } \\
\text { and ulcerations }\end{array}$ & $\begin{array}{l}\text { Easy to use, } \\
\text { 4-point scale }(0-3)\end{array}$ & No validated definition of $\mathrm{MH}$ \\
\hline $\begin{array}{l}\text { Truelove and Witts } \\
\text { sigmoidoscopic } \\
\text { assessment }\end{array}$ & No & $\begin{array}{l}\text { Overall appearance } \\
\text { of the mucosa }\end{array}$ & $\begin{array}{l}\text { No reported } \\
\text { strengths }\end{array}$ & $\begin{array}{l}\text { No description of endoscopic lesions, } \\
\text { important interobserver variability }\end{array}$ \\
\hline Baron score & No & Bleeding & $\begin{array}{l}\text { Easy to use, } 4 \text {-point scale }(0-3), \\
\text { good interobserver correlation }\end{array}$ & $\begin{array}{l}\text { Does not include an assessment of } \\
\text { ulcerations, no validate definition of } \mathrm{MH}\end{array}$ \\
\hline $\begin{array}{l}\text { Powell-Tuck } \\
\text { signmoidoscopic } \\
\text { assessment }\end{array}$ & No & Bleeding & Easy to use, 3-point scale (0-2) & $\begin{array}{l}\text { Does not include an assessment } \\
\text { of ulcerations, no validate definition } \\
\text { of } \mathrm{MH}\end{array}$ \\
\hline $\begin{array}{l}\text { Rachmilewitz } \\
\text { endoscopic index }\end{array}$ & No & $\begin{array}{l}\text { Granulation, vascular } \\
\text { pattern, vulnerability } \\
\text { of mucosa, and } \\
\text { mucosal damage }\end{array}$ & No reported strengths & $\begin{array}{l}\text { Complex (contains } 4 \text { items with values } \\
\text { ranging from } 0 \text { to } 3 \text {, and scores range } \\
\text { from } 0 \text { to } 12 \text { points), subjective scale, } \\
\text { no validated definition of } \mathrm{MH}\end{array}$ \\
\hline $\begin{array}{l}\text { Sigmoidoscopic } \\
\text { index }\end{array}$ & No & $\begin{array}{l}\text { Erythema, friability, } \\
\text { ulceration, mucopus, } \\
\text { and vascular pattern }\end{array}$ & No reported strengths & $\begin{array}{l}\text { Complex ( } 5 \text { items with values ranging } \\
\text { from } 0 \text { to } 3 \text {, and scores ranging from } 0 \\
\text { to } 16 \text { points), subjective scale (normal, } \\
\text { mild, moderate, severe), no validated } \\
\text { definition of } \mathrm{MH}\end{array}$ \\
\hline $\begin{array}{l}\text { Sigmoidoscopic } \\
\text { inflammation } \\
\text { grade score }\end{array}$ & No & $\begin{array}{l}\text { Edema, vascular pattern, } \\
\text { granularity, friability, } \\
\text { bleeding and ulcers }\end{array}$ & Easy to use, 4-point scale & No validated definition of $\mathrm{MH}$ \\
\hline $\begin{array}{l}\text { Sutherland mucosal } \\
\text { appearance } \\
\text { assessment }\end{array}$ & No & $\begin{array}{l}\text { Friability, exudation, } \\
\text { and bleeding }\end{array}$ & Easy to use, 4-point scale (0-3) & $\begin{array}{l}\text { Subjective scale, no validated } \\
\text { definition of } \mathrm{MH}\end{array}$ \\
\hline $\begin{array}{l}\text { Modified Baron } \\
\text { score }\end{array}$ & No & $\begin{array}{l}\text { Friability, vascular pattern, } \\
\text { bleeding, and ulceration }\end{array}$ & Easy to use, 5 -point scale (0-4) & No validated definition of $\mathrm{MH}$ \\
\hline
\end{tabular}

IBD, inflammatory bowel disease; $\mathrm{MH}$, mucosal healing. 
tients who achieved endoscopic remission showed better prognosis than those who did not. This allows clinicians to predict the potential for mucosal healing to affect the progress of disease. ${ }^{27-29}$ In the ACCENT I trial, patients who sustained mucosal healing through the ongoing use of infliximab were less likely to be hospitalized, operated, and treated in intensive care units. Most cases of Crohn's disease involve inflammatory lesions at the time of occurrence, without perforation or stenosis as a consequence of fibrosis. As the disease progresses, however, the inflammation recurs, resulting in stenosis or perforation. As a result, a more proactive effort has become common to impact the progression of the disease. ${ }^{30} \mathrm{Com}-$ pared to Crohn's disease, colonic mucosa heals better in the case of ulcerative colitis. The oral or transanal delivery of 5aminosalicylic acid has been found to treat mucosa, and steroid therapy showed efficacy of inducing mucosal healing although not accompanied by maintenance of the mucosal healing. There are currently no research findings on the impact of immunosuppressants upon mucosal healing in ulcerative colitis. With infliximab therapy, however, mucosal healing serves as a predictor for long-term remission. Whether infliximab can prevent the development of megacolon, dysplasia or cancer has yet to be established. ${ }^{31}$ The Crohn's Disease Endoscopic Index of Severity was developed as an index for assessing changes in mucosal activity related to Crohn's disease. Although the index can be beneficial, it is not convenient to perform; therefore, Simple Endoscopic Score of Crohn's Disease (SESCD) was developed. However, SESCD has not yet been approved for the complete remission criteria. ${ }^{32}$ Rutgeerts score ${ }^{33}$ is utilized to predict the clinical recurrence in subclinical patients with recurrent ulcers in the neoterminal ileum following surgery as shown in Table 1. Endoscopic indices of severity most commonly used in ulcerative colitis are listed in Table $2 .{ }^{34-36}$

\section{CONCLUSIONS}

The prevalence of inflammatory bowel disease is steadily increasing in Korea, and there is growing interest among doctors in its treatment. Practitioners should be well informed of the colonoscopically diagnosable lesions in order to prevent misidentification of other diseases as inflammatory bowel disease, leading to overtreatment and to avoid misdiagnosis, which could delay treatment. Effort is needed to carefully select treatment approach appropriate for each patient by providing a precise diagnosis on the extent and degree of lesions as well as to accurately delineate the lesions to assure that they are compared in subsequent rounds of follow-up monitoring in order to allow redetermination and adjustment of treatment.

\section{Conflicts of Interest}

The author has no financial conflicts of interest.

\section{REFERENCES}

1. Yang SK, Byeon JS. Diagnosis and Treatment of Colonoscopy. Seoul: Koonja; 2009.

2. Choi KY. Endoscopic manifestation of inflammatory bowel disease: ulcerative colitis. In: Proceedings of the 19th Seminar of Korean Society of Gastrointestinal Endoscopy; 1998 Aug 30-Sep 3; Seoul, Korea. Seoul: Korean Society of Gastrointestinal Endoscopy; 1998. p. 47-54.

3. Yang SK. Endoscopic diagnosis of ulcerative colitis. In: Proceedings of the 22nd Seminar of Korean Society of Gastrointestinal Endoscopy; 2003 Mar 26; Seoul, Korea. Seoul: Korean Society of Gastrointestinal Endoscopy; 2000. p. 201-218.

4. Kim TI. Endoscopic differentiation of inflammatory lesions: IBD. Korean J Gastrointest Endosc 2003;27:119-125.

5. Chutkan RK, Wayne JD. Endoscopy in inflammatory bowel disease. In: Kirsner JB, ed. Inflammatory Bowel Disease. 5th ed. Baltimore: Williams and Wilkins; 2000. p. 453-477.

6. Bernstein CN, Shanahan F, Anton PA, Weinstein WM. Patchiness of mucosal inflammation in treated ulcerative colitis: a prospective study. Gastrointest Endosc 1995;42:232-237.

7. Matsumoto T, Nakamura S, Shimizu M, Iida M. Significance of appendiceal involvement in patients with ulcerative colitis. Gastrointest Endosc 2002;55:180-185.

8. Yang SK, Jung HY, Kang GH, et al. Appendiceal orifice inflammation as a skip lesion in ulcerative colitis: an analysis in relation to medical therapy and disease extent. Gastrointest Endosc 1999;49:743-747.

9. Deutsch DE, Olson AD. Colonoscopy or sigmoidoscopy as the initial evaluation of pediatric patients with colitis: a survey of physician behavior and a cost analysis. J Pediatr Gastroenterol Nutr 1997;25:26-31.

10. Kim WH. Endoscopic manifestation of inflammatory bowel disease: Crohn's disease. In: Proceedings of the 19th Seminar of Korean Society of Gastrointestinal Endoscopy; 1998 Aug 30-Sep 3; Seoul, Korea. Seoul: Korean Society of Gastrointestinal Endoscopy; 1998. p. 55-67.

11. Kim HJ. Crohn's disease. In: Proceedings of the 22nd Seminar of Korean Society of Gastrointestinal Endoscopy; 2003 Mar 26; Seoul, Korea. Seoul: Korean Society of Gastrointestinal Endoscopy; 2000. p. 209-215.

12. Fujimura Y, Kamoi R, lida M. Pathogenesis of aphthoid ulcers in Crohn's disease: correlative findings by magnifying colonoscopy, electron microscopy, and immunohistochemistry. Gut 1996;38:724-732.

13. Ramzan NN, Leighton JA, Heigh RI, Shapiro MS. Clinical significance of granuloma in Crohn's disease. Inflamm Bowel Dis 2002;8:168-173.

14. Korelitz BI, Sommers SC. Rectal biopsy in patients with Crohn's disease. Normal mucosa on sigmoidoscopic examination. JAMA 1977;237: 2742-2744.

15. Herrerías JM, Caunedo A, Rodríguez-Téllez M, Pellicer F, Herrerías JM Jr. Capsule endoscopy in patients with suspected Crohn's disease and negative endoscopy. Endoscopy 2003;35:564-568.

16. Kim YH. Common errors in the diagnosis process. Intest Res 2003;1: 106-110.

17. Pera A, Bellando P, Caldera D, et al. Colonoscopy in inflammatory bowel disease. Diagnostic accuracy and proposal of an endoscopic score. Gastroenterology 1987;92:181-185.

18. Moum B, Ekbom A, Vatn MH, et al. Clinical course during the 1st year after diagnosis in ulcerative colitis and Crohn's disease. Results of a large, prospective population-based study in southeastern Norway, 1990-93. Scand J Gastroenterol 1997;32:1005-1012.

19. Alcántara M, Rodriguez R, Potenciano JL, Carrobles JL, Muñoz C, Gomez R. Endoscopic and bioptic findings in the upper gastrointestinal tract in patients with Crohn's disease. Endoscopy 1993;25:282-286.

20. Lo SK, Zaidel O, Tabibzadeh S, et al. Utility of wireless capsule endoscopy and IBD serology in re-classifying indeterminatecolitis. Gastroenterology 2003;124:s1310. 
21. Tedesco FJ, Hardin RD, Harper RN, Edwards BH. Infectious colitis endoscopically simulating inflammatory bowel disease: a prospective evaluation. Gastrointest Endosc 1983;29:195-197.

22. Fochios SE, Korelitz BI. The role of sigmoidoscopy and rectal biopsy in diagnosis and management of inflammatory bowel disease: personal experience. Am J Gastroenterol 1988;83:114-119.

23. Matsumoto T, Iida M, Kimura Y, Fujishima M. Culture of colonoscopically obtained biopsy specimens in acute infectious colitis. Gastrointest Endosc 1994;40(2 Pt 1):184-187.

24. Surawicz CM, Belic L. Rectal biopsy helps to distinguish acute selflimited colitis from idiopathic inflammatory bowel disease. Gastroenterology 1984;86:104-113.

25. Meucci G, Vecchi M, Astegiano M, et al. The natural history of ulcerative proctitis: a multicenter, retrospective study. Gruppo di Studio per le Malattie Infiammatorie Intestinali (GSMII). Am J Gastroenterol 2000;95:469-473.

26. Langholz E, Munkholm P, Davidsen M, Nielsen OH, Binder V. Changes in extent of ulcerative colitis: a study on the course and prognostic factors. Scand J Gastroenterol 1996;31:260-266.

27. Baron JH, Connell AM, Lennard-Jones JE. Variation between observers in describing mucosal appearances in proctocolitis. Br Med J 1964; 1:89-92.

28. Alemayehu G, Järnerot G. Colonoscopy during an attack of severe ulcerative colitis is a safe procedure and of great value in clinical decision making. Am J Gastroenterol 1991;86:187-190.

29. Modigliani R, Mary JY, Simon JF, et al. Clinical, biological, and endoscopic picture of attacks of Crohn's disease. Evolution on prednisolone. Groupe d'Etude Thérapeutique des Affections Inflammatoires Digestives. Gastroenterology 1990;98:811-818.

30. Hanauer SB, Feagan BG, Lichtenstein GR, et al. Maintenance infliximab for Crohn's disease: the ACCENT I randomised trial. Lancet 2002;359:1541-1549.

31. Pineton de Chambrun G, Peyrin-Biroulet L, Lémann M, Colombel JF. Clinical implications of mucosal healing for the management of IBD. Nat Rev Gastroenterol Hepatol 2010;7:15-29.

32. Sipponen T, Nuutinen H, Turunen U, Färkkilä M. Endoscopic evaluation of Crohn's disease activity: comparison of the CDEIS and the SESCD. Inflamm Bowel Dis 2010;16:2131-2136.

33. Lichtenstein GR, Rutgeerts P. Importance of mucosal healing in ulcerative colitis. Inflamm Bowel Dis 2010;16:338-346.

34. Travis SP, Schnell D, Krzeski P, et al. Developing an instrument to assess the endoscopic severity of ulcerative colitis: the Ulcerative Colitis Endoscopic Index of Severity (UCEIS). Gut 2012;61:535-542.

35. Truelove SC, Witts LJ. Cortisone in ulcerative colitis; final report on a therapeutic trial. Br Med J 1955;2:1041-1048.

36. Caprilli R, Viscido A, Latella G. Current management of severe ulcerative colitis. Nat Clin Pract Gastroenterol Hepatol 2007;4:92-101. 